\title{
Coupling nebulizer system to LA- ICP-MS by a Y-shape connector and its application for signal enhancement and matrix effect supressing
}

\author{
SONG WANG, JUN WANG
}

National Institute of Metrology, Beijing 100029, P. R. China wangsong@nim.ac.cn

Laser ablation inductively coupled plasma mass spectrometry (LA-ICP-MS) is a powerful technique for in situ microanalysis due to little sample preparation, rapid throughput and high spatial resolution. The serious matrix effect is the key restraint for LA-ICP-MS. In order to enhance its analytical capabilities, endless attention has been paid to matrix effect supressing/calibration and signal enhancement since the born of LA-ICP-MS.

In this work, the laser ablation system and nebulizer system were coupled before the ICP torch using a Y-shape connector. Our original objective is to achieve online isotope dilution and solution based calibration for in situ strontium isotope analysis. Using NIST 610 as example, we accidentally found that the strontium signal intensity was affected greatly by the flow rate of the nebulizer carrier gas. As shown in figures below, the signal intensity under the optimized flow rate is 50 times higher than that under 0 $\mathrm{L} / \mathrm{min}$ carrier gas, and 5 times higher than direct laser ablation sampling. This phenomenon is coincide with Huang et $a l^{2}$ that the influence of water vapor depends on whether the hydrogen enhancement or the solvent cooling dominates the solvent effect. Furthermore, the reproducibility of measured ${ }^{87} \mathrm{Sr} /{ }^{86} \mathrm{Sr}$ by this Y-shape device was $0.03 \%$, which was significant better than direct laser ablation sampling, showing great promise in matrix effect supressing.

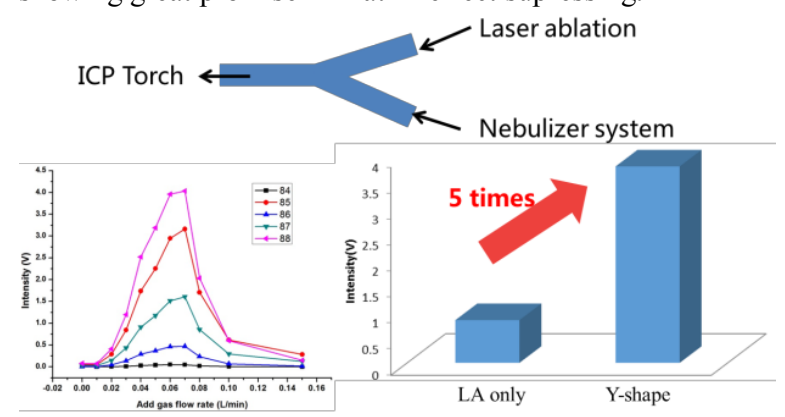

1. Zang S et al. J Anal At Spectrom. 2016; 31: 358-382.

2. Huang M et al. Anal. Chim. Acta, 2000; 413: 217-222. 